\title{
Snakebite Epidemiology in Bangladesh-A National Community Based Health and Injury Survey
}

\author{
Jahangir Hossain1, Animesh Biswas',2, Fazlur Rahman1, Saidur Rahman Mashreky1, \\ Koustv Dalal'2, Aminur Rahman'1 \\ ${ }^{1}$ Centre for Injury Prevention and Research, Bangladesh (CIPRB), Dhaka, Bangladesh \\ ${ }^{2}$ Centre for Injury Prevention \& Safety Promotion, School of Health \&Medical Sciences, \\ Örebro University, Örebro, Sweden \\ Email: hossainmdj@yahoo.com
}

Received 7 February 2016; accepted 15 March 2016; published 18 March 2016

Copyright (C) 2016 by authors and Scientific Research Publishing Inc.

This work is licensed under the Creative Commons Attribution International License (CC BY). http://creativecommons.org/licenses/by/4.0/

(c) (i) Open Access

\begin{abstract}
Insert Snakebite is a global public health issue, and in majority of cases it is undermined. Tropical and subtropical countries are most effected, Bangladesh being one of them. There is scarcity of countries' epidemiological situation in relation to snakebite poisoning. This study has looked at the epidemiological status of snakebite poisoning from national representative survey findings. Methods: A nationwide cross-sectional survey was conducted in 12 randomly selected districts of Bangladesh in 2003. A total of 171,366 households were surveyed and information was collected from 819,429 populations by face to face interview. Multi-stage cluster sampling methods were used in this survey and covered urban, rural and slum populations. Results: Annually an estimated $15,372(10.98 / 100,000)$ individuals were bitten by snakes and of them $1709(1.22 / 100,000)$ died every year. Males were found to be most vulnerable with a risk of 1.51 times higher than female. Rural populations were also 10.54 times higher at risk than the populations living in the urban areas. Among the victims $\mathbf{9 4 \%}$ were from the poor socio economic conditions. Around $43.9 \%$ of the incidences occurred during evening to midnight. Home was found the most common area for snake bite (33.6\%), and the Leg was found to be the most common site for biting (63.1\%). A total of $96.6 \%$ victims sought treatment, of them $61 \%$ sought immediate treatment from traditional healing methods. Conclusions: Present incidence of snakebite in Bangladesh has clearly shown that there is emerging public health needs for intervention that can reduce the mortality and burden of the disease in the country.
\end{abstract}

\section{Keywords}

Snake Bite, Incidence, Bangladesh

How to cite this paper: Hossain, J., Biswas, A., Rahman, F., Mashreky, S.R., Dalal, K. and Rahman, A. (2016) Snakebite Epidemiology in Bangladesh-A National Community Based Health and Injury Survey. Health, 8, 479-486.

http://dx.doi.org/10.4236/health.2016.85051 


\section{Introduction}

Snake bite constitutes a neglected public health problem globally [1]. The Snake bite has been considered to be a devastating environmental occupational injury, affecting poor rural communities like farmers, plantation workers and fishermen around the world [2]-[4]. The majority of snake bites occur in rural areas in tropical and subtropical countries of Asia, Africa and America with a high fatality rate [2]-[7]. South East Asia is considered to be most vulnerable due to its high mortality and morbidity [8]. It has also been identified that there are wide spread venomous snake species and a lack of effective snake bite control programs, which are key factors for such conditions [9]-[11]. World Health Organization reported venomous snakes caused 5.4 million bites every year around the world, of them 2.5 million suffered with envenoming and around 125,000 died [12].

Snakebite is often an under recognized public health issue in Bangladesh [13]. Geographical location and the tropical environment of Bangladesh allow the growing of different species of snakes. As a result, about 82 different species including 12 species of sea snakes are grossly available all over Bangladesh, of them 28 species are venomous [14]. Countries like Bangladesh and India conduct community based household surveys to identify its magnitude, which is far greater than the hospital based studies [15] [16]. A study conducted in 1999 estimated the incidence of 4.3 snake bites per 100,000 populations per year in Bangladesh, with approximately 2000 deaths [17]. Whereas, a recent study conducted in 2009 showed higher than previous studies, which was 623.4/100,000 person years [18]. In Bangladesh, snakebite is considered as a common health problem among the rural population. However, due to lack of nationally representative data, the exact magnitude is still unknown [9]. Considering the context of the country, there is an urgent need for exploring the present epidemiological status of snake bite in Bangladesh.

\section{Methods}

\subsection{Study Design}

A cross-sectional study was conducted during 2003 (January to December) in 12 randomly selected districts of Bangladesh and in Dhaka Metropolitan City. This encompassed a total population of 819,429. Multi-stage cluster sampling was used to choose a total sample size of 171,366 households: 88,380 from rural areas, 45,183 from district towns (urban areas), and 37,803 from Dhaka Metropolitan City. Bangladesh has a total of 64 districts. Twelve of these were chosen by simple random sampling. Each district comprises several upazilas (sub districts). One upazila was randomly selected from each selected district. An upazilas comprises a number of unions. A union is the lowest administrative unit comprising of around 20,000 people. From each upazila, two unions were selected randomly and each union was considered a cluster. All households in the union were included in the survey. The district headquarters of the 12 selected districts and Dhaka Metropolitan City constituted the urban areas. In the urban areas, Mohallas (lowest unit of the city corporation) served as clusters, which constitutes about 400 - 500 households. Systematic sampling was done to determine the required number of households.

\subsection{Sample Selection}

Anyone who was injured by snake bite and received treatment or could not perform normal activities for at least 3 days was included as a case of snake bite.

\subsection{Data Collection and Interview}

Forty-eight data collectors (all full-time employees) collected data from respondents through face-to-face interviews. Along with the researchers, six full-time supervisors were employed for the supervision and monitoring of the data collection process. Both the supervisors and data collectors were trained in the data collection process. Mothers were preferred as respondents. However, if the mother was not available the most knowledgeable members of the household were considered as respondents. Where possible, the head of household and as many members of the household as possible were present to collaborate or add detail to the respondent's interview answers. Screening forms were used to identify any mortality or morbidity in the household. A household member was defined as someone living in the same house, including domestic helpers or long-term guests who shared meals and participated in the daily activities within the household. 
The respondents were first asked whether there had been any illness or injury at home in the last 6 months. If any illnesses/injuries were identified, the interviewer proceeded with further clarification regarding the injuries. Structured questionnaires were used to identify animal related injury and later snake bite related data was extracted for further analysis. Repeat visits were made to the households where respondents were unavailable during the first visit. In spite of repeated attempts, $2.7 \%$ of households could not be interviewed. A total of 166,766 households completed participation in the study.

\subsection{Statistical Analysis}

Standard descriptive statistics were used to analyze the characteristics of snakebite patients. Mean, SD, and proportion were used where appropriate. Snake bites were presented by gender, age, and place of residence. Age was categorized in eight groups. The yearly incidence of snake bite was calculated from the occurrence of snake bite morbidity in 6 months multiplied by 2, as data was collected with a 6-month recall period. Rates were calculated with 95\% CIs. Relative risk (RR) was calculated to compare the snake bite risks in different age groups, place of residence, and gender by using a $2 \times 2$ table in EPI-Info software.

\subsection{Ethics Approval}

Ethical clearance was obtained from the Ethical Committee of the Institute of Child and Mother Health, Dhaka.

\section{Results}

\subsection{Incidence of Snake Bite in Bangladesh}

A total number of 90 snake bites were found in this nationwide cross sectional survey, of them $45.6 \%(n=41)$ were children. The incidence was 10.98/100,000 (95\% CI 8.88 to 13.44) population in a year. The incidence of fatality was $1.22 / 100,000$ (95\% CI 0.6199 to 2.175$)$ population in a year. Among the cases $65.4 \%(n=59)$ were male and $34.6 \%(n=31)$ were female. Males were found most vulnerable with a risk of 1.51 times than the female (RR 1.51; 95\% CI 1.01 to 2.25). Rural populations were also found vulnerable with a risk of around 10.54 times higher (RR 10.54; 95\% CI 4.85 to 22.71) than the populations living in the urban areas (Table 1). Mean age of victims was 20.17 (SD + 11.57) years, ranging from 1 to 50 years. Incidence among groups 15 to 19 years were found 3 times higher (RR 3.21, CI2.01 to 5.12) than the all other age group of the populations (Figure 1).

\subsection{Socio Demographic Characteristics}

Among the victims, 94\% $(n=84)$ most were from the poor socio economic conditions, whose average monthly income was tk. 3,642 (\$57). Of the victims $29.1 \%(\mathrm{n}=26)$ were students followed by housewives $18.2 \%(\mathrm{n}=16)$ and daily labor $16.3 \%(n=15)$.

Table 1. Risk factors for snake bite.

\begin{tabular}{|c|c|c|c|c|}
\hline Category & Frequency & Rate per 100,000 population/year & $\mathrm{RR}(95 \% \mathrm{CI})$ & $P$ value \\
\hline \multicolumn{5}{|l|}{ Sex } \\
\hline Male & 59 & 14.16 & RR 1.83 (CI 1.19 to 2.84$)$ & 0.002 \\
\hline Female & 31 & 7.7 & 1 & \\
\hline \multicolumn{5}{|l|}{ Place } \\
\hline Rural & 83 & 19.03 & RR 10.5 (4.855 to 22.71$)$ & 0.0000001 \\
\hline Urban & 7 & 1.08 & 1 & \\
\hline \multicolumn{5}{|l|}{ Age } \\
\hline $10-19$ yrs & 45 & 24.01 & RR 3.422 ( 2.64 to 5.173 ) & 0.0000001 \\
\hline Other ages & 45 & 7.12 & 1 & \\
\hline
\end{tabular}




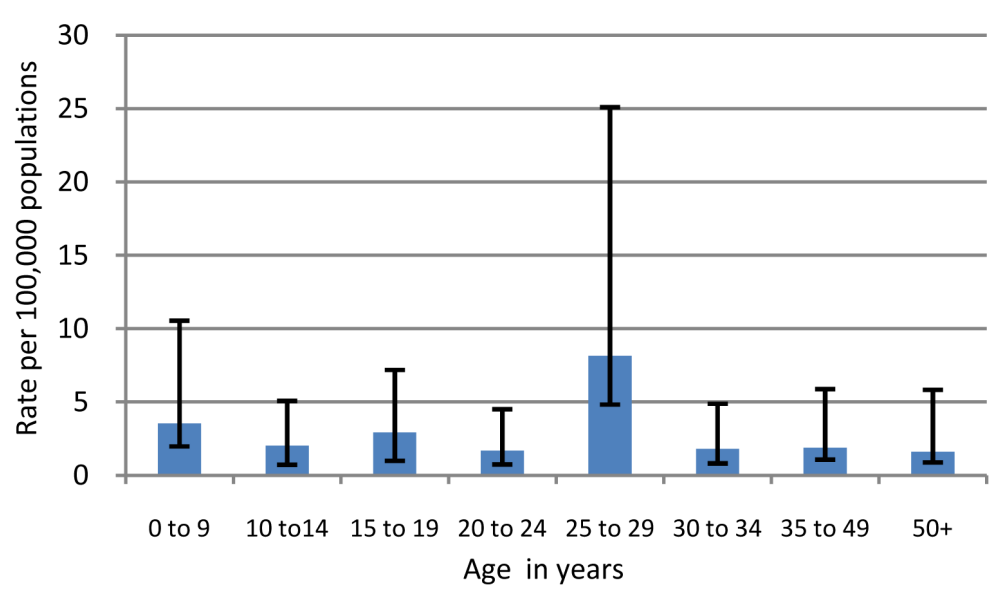

Figure 1. Snakebite incidence by age in Bangladesh.

\subsection{Place and Time of the Incidence with Area of Bite}

A total of $42.8 \%(n=38)$ episodes of snake bites took place during working with daily activities followed by walking $(20 \% \mathrm{n}=18)$ from one place to another. Home was found the most common area for snake bite $33.6 \%$ $(n=30)$ followed by street $(26 \%(n=23)$, water reservoir $25.9 \%(n=23)$ and agricultural farm $14.5 \%(n=13)$. Around $43.9 \%$ of the incidences occurred during 18.00 to 24.00 followed by 12.00 noon to 17.00 . The leg was found to be the most common area for snake bite $63.1 \%(n=57)$ followed by hand $14.5 \%(n=13)$ (Table 2).

\subsection{Health Seeking Behavior}

Among the causalities 96.6\% $(n=87)$ sought treatment from medical facilities, traditional healers, herbal medicine practitioners, religious healers. Of them $18 \%(n=15)$ sought treatment from medical facilities or registered medical professionals and around $61 \%(\mathrm{n}=55)$ sought treatment from the traditional healer or herbal medicine practitioner. Among the victims only 4.5\% $(\mathrm{n}=4)$ people were hospitalized for a short duration ranging 1 to 3 days (Figure 2).

\subsection{Others Factors}

The average costing for managing each snake bite treatment was tk. 872.16 (\$13.61). Required help for daily activities 4.35 days $(\mathrm{SD} \pm 6.58$ ). Among the victims, nobody reported in to the police station. Among the victims $52.7 \%(n=47)$ had up to a primary level of education. Among the snake bite victims, the average work days lost were 5.95 ( $S D \pm 4.520$ ). No permanent disability due to snake bites were found in this study.

\section{Discussion}

Bangladesh Health and Injury Survey (BHIS) national data has explored the annual incidence of snakebite which was 10.98/100,000 populations. Annually an estimated 15,372 individuals were bitten by snakes and of them 1,709 died in Bangladesh. This estimated rate was 3 times higher than the survey rate conducted in 1999 by Sarker et al. [17]. While as, another national epidemiological survey stated incidence density of snake bite was $623.4 / 100,000$ persons years (95\% C I 513.4 - 789.2/100,000 person years) [18]. The designing of the study and estimation of sample size may be many times higher incidence than the present study. Whereas, the national mortality survey in India showed an annual death due to snake bite of 4.1/10,000 [19]. Our study calculated annual incidence of death was 1.22/100,000 per year.

Younger age ranging from 10 to 19 years was found as risk factor and the main victims of snake bite injury in Bangladesh. The relative risk was found 3.42 times higher than the other combined age of the population. Similar results were reported from studies conducted in Nepal, Malaysia and Sri Lanka [20]-[24].

Males tended to have higher snake bite injury rates rather than females. In this study males were found to be 1.83 (95\% CI 1.19 to 2.84) times higher at risk than females. Studies conducted in neighboring countries in India, Nepal, Sri Lanka and Pakistan suggested similar results [7] [19] [23] [25]-[30]. The male predominance in 
Table 2. Details of snake bite in Bangladesh.

\begin{tabular}{|c|c|}
\hline Factors & Percentages \\
\hline \multicolumn{2}{|l|}{ Occupation } \\
\hline Student & 29.1 \\
\hline Farmer & 12.8 \\
\hline Daily laborer & 16.3 \\
\hline Business & 4.5 \\
\hline Housewife & 18.2 \\
\hline Unemployed & 11 \\
\hline Others & 8.2 \\
\hline \multicolumn{2}{|c|}{ Activities of the person prior biting } \\
\hline Work & 42.8 \\
\hline Playing (in/outdoor) & 7.3 \\
\hline Traveling & 20 \\
\hline Others & 29.8 \\
\hline \multicolumn{2}{|l|}{ Place of bite } \\
\hline Home & 33.6 \\
\hline Highway/street & 26 \\
\hline Farming area & 14.5 \\
\hline Water reservoir & 25.9 \\
\hline \multicolumn{2}{|l|}{ Time of bite } \\
\hline Midnight to 6 am & 7.2 \\
\hline 6 am to 12 noon & 16.2 \\
\hline 12 noon to $18 \mathrm{pm}$ & 32.7 \\
\hline $18 \mathrm{pm}$ to midnight & 43.9 \\
\hline \multicolumn{2}{|l|}{ Site of biting } \\
\hline Face & 2.9 \\
\hline Hand & 19.4 \\
\hline Leg & 63.1 \\
\hline Others & 14.5 \\
\hline \multicolumn{2}{|l|}{ Prior involvement } \\
\hline Playing/disturbing & 12.9 \\
\hline No prior involvement & 63.7 \\
\hline Others & 23.6 \\
\hline \multicolumn{2}{|l|}{ Education level } \\
\hline Illiterate & 26.8 \\
\hline Up to 5 grade & 25.9 \\
\hline 6 to 12 grade & 39.2 \\
\hline Child $<5$ yrs & 8.2 \\
\hline \multicolumn{2}{|l|}{ Religion } \\
\hline Muslim & 85.3 \\
\hline Hindu & 14.7 \\
\hline \multicolumn{2}{|l|}{ Place of living } \\
\hline Urban & 7.8 \\
\hline Rural & 92.2 \\
\hline \multicolumn{2}{|l|}{ Sex } \\
\hline Male & 65.4 \\
\hline Female & 34.6 \\
\hline \multicolumn{2}{|l|}{ Treatment sought } \\
\hline Yes & 96.6 \\
\hline No & 3.4 \\
\hline
\end{tabular}




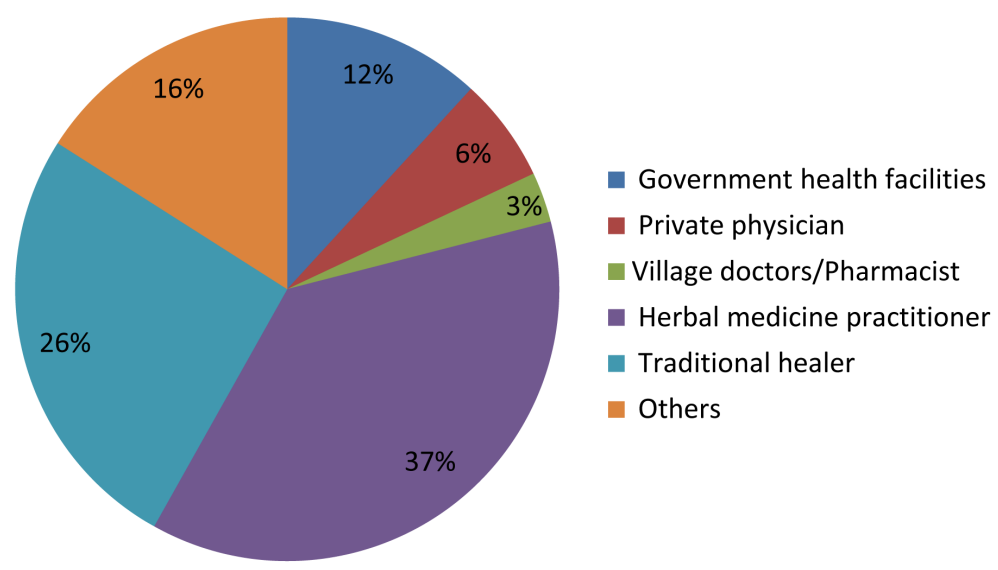

Figure 2. Health seeking behavior among the causalities.

this group was most likely due to gender roles in daily activities as males work in the field and spend more times outside whereas female work mainly in the house premises in Bangladesh.

Most of the victims were farmers, daily labors, students and housewives and from the poor socio economic conditions living in rural areas. Biting occurs mostly when individuals are at work, walking in the street, engaging activities such as cultivation, fishing, and plantation or tending crops. Similarly results found in other studies [2] [7] [30]. Affecting people with mostly low economic context is considered as an economic burden for the nation [31].

The majority of the victims (63\%) received snake bites in lower extremities. Similar results were found in some other studies in neighboring countries [11] [20] [23] [29] [32] [33]. The main reason may be that people who stood on the snake, were easily bitten as the snake can easily bite people while they are standing or running. Biting in the face was common in the agriculture sector, the reason being that the face had became the nearest target, during the collection of crops like rice, vegetables and fruits.

In Bangladesh traditionally snakebite treatment is dominated by traditional healers and herbal medicine practitioners. In this study only $61 \%$ causalities sought help from traditional healer or herbal medicine practitioners and only $17.4 \%$ sought medical help from Government facilities or registered doctors as a preference of first time treatment. Findings from neighboring countries also show that traditional healer's predominantly provided the first line of treatment [10] [11] [34] [35].

\section{Conclusion}

Snake bite is an important but neglected public health issue, especially for populations living in the rural areas. The rural community identifies poor health seeking behavior, including treatment taken by the traditional healers and medicine shopkeepers, village doctors etc. Mass awareness is required to develop mental capacity among the villagers to take appropriate precautions, whilst being given the right interventions for the safe reduction of snake poisoning in Bangladesh.

\section{References}

[1] World Health Organization (2016) A Multicomponent Strategy to Improve the Availiblity of Anivenom for Trating Snaebite Envenoming. http://www.who.int/bulletin/volumes/92/7/13-132431/en/

[2] Williams, D., Gutiérrez, J.M., Harrison, R., Warrell, D., White, J., Winkel, K.D., et al. (2010) The Global Snake Bite Initiative: An Antidote for Snake Bite. The Lancet, 375, 89-91. http://dx.doi.org/10.1016/S0140-6736(09)61159-4

[3] Kasturiratne, A., Wickremasinghe, A.R., De Silva, N., Gunawardena, N.K., Pathmeswaran, A., Premaratna, R., et al. (2008) The Global Burden of Snakebite: A Literature Analysis and Modelling Based on Regional Estimates of Envenoming and Deaths. PLoS Medicine, 5, 1591-1604. http://dx.doi.org/10.1371/journal.pmed.0050218

[4] Warrell, D.A. (2010) Snake Bite. The Lancet, 375, 77-88. http://dx.doi.org/10.1016/S0140-6736(09)61754-2

[5] White, J., Warrell, D., Eddleston, M., Currie, B.J., Whyte, I.M. and Isbister, G.K. (2003) Clinical Toxinology-Where Are We Now? Journal of Toxicology-Clinical Toxicology, 41, 263-276. http://dx.doi.org/10.1081/CLT-120021112 
[6] White, J. (2000) Bites and Stings from Venomous Animals: A Global Overview. Therapeutic Drug Monitoring, 22, 6568. http://dx.doi.org/10.1097/00007691-200002000-00014

[7] Halesha, B.R., Harshavardhan, L., Lokesh, A.J., Channaveerappa, P.K. and Venkatesh, K.B. (2013) A Study on the Clinico-Epidemiological Profile and the Outcome of Snake Bite Victims in a Tertiary Care Centre in Southern India. Journal of Clinical and Diagnostic Research, 7, 122-126.

[8] Ghose, A. and Faiz, A. (2015) Snake Envenomation in Bangladesh. Clinical Toxinology in Aisa Pacific and Africa, 233-249.

[9] Alirol, E., Sharma, S.K., Bawaskar, H.S., Kuch, U. and Chappuis, F. (2010) Snake Bite in South Asia: A Review. PLoS Neglected Tropical Diseases, 4, e603. http://dx.doi.org/10.1371/journal.pntd.0000603

[10] Sharma, S.K., Chappuis, F., Jha, N., Bovier, P.A., Loutan, L. and Koirala, S. (2004) Impact of Snake Bites and Determinants of Fatal Outcomes in Southeastern Nepal. The American Journal of Tropical Medicine and Hygiene, 71, 234238.

[11] Hati, A.K., Mandal, M., De, M.K., Mukherjee, H. and Hati, R.N. (1992) Epidemiology of Snake Bite in the District of Burdwan, West Bengal. Journal of the Indian Medical Association, 90, 145-147.

[12] Chippaux, J.P. (1998) Snake-Bites: Appraisal of the Global Situation. Bulletin of the World Health Organization, 76, 515-524.

[13] Abms, A. and Akmm, I. (2015) Snake Bite as a Public Health Problem: Bangladesh Perspective. Birdem Medical Journal, 5, 24-29.

[14] Faiz, M.A., Hossain, M., Amin, R. and Ga, A.B. (2008) National Guideline of Management of Snake Bite. 2nd Edition, DGHS, Dhaka.

[15] Harris, J.B., Faiz, M.A., Rahman, M.R., Jalil, M.M.A., Ahsan, M.F., Theakston, R.D.G., et al. (2010) Snake Bite in Chittagong Division, Bangladesh: A Study of Bitten Patients Who Developed No Signs of Systemic Envenoming. Royal Society of Tropical Medicine and Hygiene, 104, 320-327. http://dx.doi.org/10.1016/j.trstmh.2009.12.006

[16] Gutierrez, J.M. (2014) Current Challenges for Confronting the Public Health Problem of Snakebite Envenoming in Central America. Journal of Venomous Animals and Toxins including Tropical Diseases, $20,7$. http://dx.doi.org/10.1186/1678-9199-20-7

[17] Sarker, M.S. and Sarker, N.J.P.S. (1999) Epidemiological Survey of Snake Bite Incidences in Bangladesh. Journal of Biological Sciences, 8, 53-68.

[18] Rahman, R., Faiz, M.A., Selim, S., Rahman, B., Basher, A., Jones, A., et al. (2010) Annual Incidence of Snake Bite in Rural Bangladesh. PLoS Neglected Tropical Diseases, 4, e860. http://dx.doi.org/10.1371/journal.pntd.0000860

[19] Mohapatra, B., Warrell, D.A., Suraweera, W., Bhatia, P., Dhingra, N., Jotkar, R.M., et al. (2011) Snakebite Mortality in India: A Nationally Representative Mortality Survey. PLoS Neglected Tropical Diseases, 5, 1-8. http://dx.doi.org/10.1371/journal.pntd.0001018

[20] Sharma, S.K., Khanal, B., Pokhrel, P., Khan, A.K.S. (2003) Snake Bite Reappraisal of the Situation in Eastern Nepal. Toxicon, 41, 285-289. http://dx.doi.org/10.1016/S0041-0101(02)00289-1

[21] Jamaiah, I., Rohela, M., Ng, T.K., Ch’ng, K.B., The, Y.S. et al. (2006) Retrospective Prevalence of Snakebites from Hospital Kuala Lumpur (HKL). Southeast Asian Journal of Tropical Medicine and Public Health, 37, 200-205.

[22] Zulkifli, A. and Hashim, M.H.K.A. (1995) Snake Bites in Kelantan, Peninsular Malaysia. Tropical Biomedicine, 12, 14.

[23] Kularatne, S.A.M. (2003) Epidemiology and Clinical Picture of the Russell's Viper (Daboia Russelii Russelii) Bite in Anuradhapura, Sri Lanka: A Prospective Study of 336 Patients. The Southeast Asian Journal of Tropical Medicine and Public Health, 34, 855-862.

[24] Hansdak, S.G., Lallar, K.S., Pokharel, P., Shyangwa, P., Karki, P. and Koirala, S. (1998) A Clinico-Epidemiological Study of Snake Bite in Nepal. Tropical Doctor, 28, 223-236.

[25] Brunda, G. and Sashidhar, R.B. (2007) Epidemiological Profile of Snake-Bite Cases from Andhra Pradesh Using Immunoanalytical Approach. Indian Journal of Medical Research, 125, 661-668.

[26] Suchithra, N., Pappachan, J.M. and Sujathan, P. (2008) Snakebite Envenoming in Kerala, South India: Clinical Profile and Factors Involved in Adverse Outcomes. Emergency Medicine Journal, 25, 200-204. http://dx.doi.org/10.1136/emj.2007.051136

[27] Bawaskar, H.S. and Bawaskar, P.H. (2002) Profile of Snakebite Envenoming in Western Maharashtra, India. Transactions of the Royal Society of Tropical Medicine and Hygiene, 96, 79-84. http://dx.doi.org/10.1016/S0035-9203(02)90250-6

[28] Sharma, S.K., Khanal, B., Pokhrel, P., Khan, A. and Koirala, S. (2003) Snakebite-Reappraisal of the Situation in East- 
ern Nepal. Toxicon, 41, 285-289. http://dx.doi.org/10.1016/S0041-0101(02)00289-1

[29] Suleman, M.M., Shahab, S. and Rab, M.A. (1998) Snake Bite in the Thar Desert. Journal of the Pakistan Medical Association, 48, 306-368.

[30] Monteiro, F.N.P., Kanchan, T., Bhagavath, P., Kumar, G.P., Menezes, R.G. and Yoganarasimha, K. (2012) Clinico-Epidemiological Features of Viper Bite Envenomation: A Study from Manipal, South India. Singapore Medical Journal, 53, 203-207.

[31] Anandilal, R. and Ayurveda, P. (2012) Education AM, Rural N, Delhi N, Pharmacology R. Short Report, 3, 20122013.

[32] Ariaratnam, C.A., Sheriff, M.H.R., Theakston, R.D.G. and Warrell, D.A. (2008) Distinctive Epidemiologic and Clinical Features of Common Krait (Bungarus caeruleus) Bites in Sri Lanka. The American Journal of Tropical Medicine and Hygiene, 79, 458-462.

[33] Ghosh, M. and Chatterjee, S. (1978) Cultivation of Mentha Citrata Ehrh in Burdwan District, West Bengal. Proceedings of the Indian Academy of Science, 87, 157-160.

[34] Gomes, A., Das, R., Sarkhel, S., Mishra, R., Mukherjee, S., Bhattacharya, S., et al. (2010) Herbs and Herbal Constituents Active against Snake Bite. Indian Journal of Experimental Biology, 48, 865-878.

[35] Faiz, M.A. (2006) Snake Bite in Bangladesh. The Orion, 23, 322. 